\title{
Capital Matters: Social Sustaining Capital and the Development of Black Student-Athletes
}

\author{
Albert Y. Bimper \\ Colorado State University
}

\begin{abstract}
How is social capital nurtured and made meaningful in the development of black student-athletes in historically white institutional (HWI) settings? Research explicitly exploring an understanding of nurturing social capital related to the development of black student-athletes is scarce. This collective case study investigates black student-athletes' accrual and meaning-making of social capital in historically white settings of higher education and intercollegiate athletics. The data analysis, guided by conceptual frames of social capital theory and critical race theory, revealed two emergent themes identified as 1) Connected with and through community and 2) Cultivating cross-cultural ties. Findings revealed similarities and nuanced differences in social capital realized by participants across two student-athlete development programs at different HWIs of higher education. Implications for intercollegiate student-athlete program designs and pedagogical implementations are discussed. Further implications from this research contribute to scholars' deeper understandings of the contextualized sociocultural development of black intercollegiate student-athletes.
\end{abstract}

Keywords: student-athletes, social capital, race, intercollegiate athletics, student development

The ways in which individuals nurture social ties and use social networks is fundamental to one's development and their ability to navigate in and about multiple contexts. Scholarly inquiries to explore and undrape deeper understandings of the experiences and dilemmas faced by black collegiate student-athletes abound in studies of the intersection between race, sport and higher education. As such, scholarly interests have been vastly focused on investigating how manifestations of race intercede the development and experiences of black collegiate studentathletes (Beamon \& Bell, 2006, 2011; Bimper, 2014ab; Bimper, Harrison \& Clark, 2013; Donner, 2005). The need to survey the role that race plays in the lives as well as the development, specifically social capital development (Coleman, 1988; Putnam, 2000), of black student-athletes is further accentuated when recognizing

The author is with Ethnic Studies, Colorado State University, Fort Collins, CO. Address author correspondence to Albert Y. Bimper at albert.bimper@colostate.edu. 
the influential sociocultural climate of historically White settings across many national collegiate athletic association (NCAA) member institutions.

Nearly one fifth of the male student-athlete population across Divisions I, II, III in 2013-2014 composed of black male student-athletes. Black females made up $15 \%$ of all female student-athletes participating at the Division I level in 2013-2014 (Lapchick, Fox, Guiao, \& Simpson, 2015). Furthermore, black student-athletes were highly concentrated in football at $52.9 \%$ across NCAA football bowl series (FBS) schools and in men and women's basketball at 57.6 and 51.1\%, respectively, across the Division I level in 2013-2014 (Lapchick, Fox, Guiao, \& Simpson). The holistic development, including the academic, personal and social development of these black student-athletes is contingent far beyond their participation in sport and can have a direct impact on NCAA athletic departments' prestige and success (e.g., athlete retention, athlete academic outcomes).

Morris (2004) examined the application of social capital theory to the schooling of black students by situating the broader historical context concerning racial ideology within contemporary discourse. In this study, he explored counter-narratives that interrogate the privileging of white self-interest and challenge how race and racism affects the social capital of black persons. Morris argues for further consideration of how race and racism affect the extent to which black persons acquire social capital in white settings. The social-cultural influences as a by-product of the milieu of white settings garners salient consideration when exploring the development of black student-athletes participating in collegiate sport at institutions of higher education.

Coupling institutional investments and purposeful programmatic design for developing social relations by which student-athletes can acquire essential and meaningful resources could beneficially serve black student-athletes to socially and culturally traverse white settings, such as institutions of higher education. There is a dearth of research that explicitly explores an understanding of generating social capital related to the development of black student-athletes. Hence, the purpose of this study was to investigate how intercollegiate black student-athletes accrue and make meaning of social capital through culturally relevant and responsive studentathlete development programs within the contexts of historically white campus settings. The interpretive analysis in the current study draws upon the theoretical frames of social capital theory and critical race theory to consider how the nurturing of social capital is influenced by the sociocultural factor of race.

\section{Theoretical and Conceptual Frames}

\section{Social Capital Theory}

Social capital literature and research (e.g., Bourdieu, 1986; Burt, 1992; Coleman, 1988, 1990; Lin, 1999; Portes, 1998; Putnam, 1993, 1995) offers a viable foundation to further consider the application of the social capital concept toward a better understanding of the nuances of student-athlete development. Portes (1998) argues the "...novelty and heuristic power of social capital..." is captured in both the positive outcomes of sociability and connectivity as well as situating sociability in the broader context of capital gained by linkages to power and influence sources (p. 2 ). Broadly stated, the concept of social capital is positioned by the potential of means, assets and resources gained through the formation and maturity of social ties. 
Bourdieu's (1985) analysis of the phenomena of social capital offers a robust, theoretical characterization of the concept. Bourdieu frames social capital as the following:

The aggregate of the actual or potential resources which are linked to possession of a durable network of more or less institutionalized relationships of mutual acquaintance or recognition (p. 248).

Bourdieu's refinement of social capital brings focus to the notion that individuals develop relationships with intentionality to reap the benefits that may come about later on from those social group relations. A key stance within Bourdieu's proposition of social capital is the dual elements of the concept. First of which, he argues it is the sociability of the relationship that permits one to realize access to the actual or potential resources possessed by others within the social tie. The second element of social capital, as described by Bourdieu, is the amount and quality of resources realized by an individual.

In addition to Bourdieu, the roots of social capital can be traced back to the work of American sociologist Coleman (1988). Most notably, Coleman postulates that social capital plays a significant role in the creation of other capital, in particular human capital. Human capital is illustrated by acquisition of skills, knowledge and capabilities that authorize persons to act in new ways (Coleman, 1988). According to Coleman, social capital is productive, enabling the possibility of achieving certain ends that would otherwise seem unattainable in the absence of social capital. Distinguished by its function, Coleman has defined social capital as:

...not a single entity but a variety of different entities, with two elements in common: they all consist of some aspect of social structures, and they facilitate certain actions of actors-whether persons or corporate actors-within the structure (p. S98).

From this definition, Coleman argues that social capital is embedded within the structures of relations and relationships between and among actors. To advance his conceptualization of social capital, he identifies three forms of social capital: obligations and expectations dependent upon the trustworthiness of structures, particularly the social environment of relations, the potential for informationflow among social structures, and effective norms linked to sanctions. In this context, Coleman (1988) argues an actor performs within a social tie for another, establishing an expectation of reciprocity and an obligation on their part as the initiating actor.

The conceptual developments of social capital have not been limited to the work of sociologists. As a political scientist, Putnam's $(1995,2000)$ conceptualization of social capital builds upon and detours from both Bourdieu and Coleman's interpretations of social capital. In accordance to Bourdieu and Coleman, the existence of social capital is based on perspectives of relationships between actors and that of actors within a social group; thus offering potential benefits resulting from their insertion with and among social ties of networks and social structures. Alternatively, Putnam's interpretation of social capital extends beyond the properties of individuals to that of broader communities. With a focus placed upon communities and civic engagement, Putnam (1993) postulates: 
By analogy with notions of physical capital and human capital-tools and training that enhance individual productivity-"social capital" refers to features of social organization such as networks, norms, and social trust that facilitate coordination and cooperation for mutual benefit (p. 35).

Putnam's work offers a window for illuminating perceptive dimensions of social capital. Putnam (1995) perceived social capital not as a one-dimensional concept, but rather arguing for greater clarity of the multidimensional elements of social capital. Accordingly, Putnam (2000) makes a case for a diversity of social capital by differentiating between forms of social capital cultivated by social ties that promote deeper connectivity of homogenous groups from a form of social capital developed out of furnishing links between groups with more heterogeneity.

Social relations are ubiquitous within the sociocultural climate of intercollegiate athletics situated in the backdrop of institutions of higher education. Here, sociocultural climate refers to the nuances of social, cultural, political, economic, and historical influences on the function and operations of collegiate sport and campus life at universities and colleges. For student-athletes, developing their stocks of capital stands as a critical venture for their holistic development. In particular, their investment and gains of social capital may yield them significant returns on investment in multiple arenas (e.g., social, academic, personal) of their lives in the present and in the future. This research utilizes the conceptual lens of social capital to advance knowledge and understandings of black student-athlete development.

\section{Critical Race Theory}

Racial discourses and nuanced understandings of racism, particularly associated to black student-athletes' development, are situated and unfold within the sociocultural climate that exist at the interface of intercollegiate athletics and higher education settings. Critical race theory (Bell, 1992, Crenshaw, Gotanda, Peller, \& Thomas, 1995; Delgado, 1988; Tate, 1997: CRT) offers an operative lens to explore how black student-athletes develop stocks of capital with specific regard for the influence of race. Here, critical race theory functions as an interpretive framework to deconstruct abstract liberalists' discourse regarding the social construct of race so to illuminate overt, systemic and nuanced manners in which the permanence of racism and the contemporary role of race manifests throughout institutions of American society, such as sport and higher education. There exist an increasing body of scholarship by sport scholars that employs a CRT frame to explore black student-athletes' perceptions and experiences of racism linked to student development, mentorship, academic outcomes, and sport management (e.g., Bimper, 2014b; Bimper, Harrison, \& Clark, 2013; Carter \& Hart, 2010; Carter-Francique, Hart, \& Steward, 2013; Donner, 2005; Singer, 2005). The overarching agenda and impact of CRT is to problematize the manners by which race has historically and presently influences the lives of persons of color as well as the functioning and operations of a society undergoing constant change. Accordingly, CRT scholarship represents a critique of both liberal and conservative ideologies (Tate, 1997). Several defining tenets of CRT, particularly within in educational contexts, inform systematic inquiry, pedagogy, curricula and programmatic design.

First, CRT acknowledges that race and racism is deeply embedded, pervasive, and a perpetual component to the function and operation of American life through 
the tenet of the intercentricity of race and racism (Bell, 1992). CRT scholars' "realist view" of the permanence of racial ideology and the dominant, fundamental role of race that underpins American society recognizes widespread and deeply rooted effects throughout its institutions legally, culturally, and psychologically (Bell, 1992; Lawrence, 1995; Tate, 1997). Therefore, CRT recognizes matters of race and racism as normal in the lives of persons of color, serving as an anchor and intersecting juncture with other forms of subordination (Crenshaw, 1991; Matsuda, Lawrence, Delgado, \& Crenshaw, 1993). Secondly, CRT challenges the propagation of traditional notions of liberal ideology_objectivity, race neutrality, meritocracy and color-blindness-through its tenet of skepticism of dominate ideology. The critique of liberalism, in this sense, problematizes how said abstract liberalist ideologies exploit certain desirable discourse such as equality, an even playing field and colorblindness camouflaging an inherent justification and protection of white self-interests and white privilege (Bonilla-Silva, 2009; Solórzano, 1997; Tate, 1997). These ideologies are often transmitted as stories_-stock explanations-constructed as sincere fictions to maintain privilege and to rationalize and preserve inequitable conditions (Crenshaw, 1988; Delgado, 1989, 1990; Feagin, Vera, \& Batur, 2001; Gotanda, 1991; Ladson-Billings \& Tate, 1995). Third, CRT scholarship locates the centrality of experiential knowledge as a key tenet to give permission and value for one to name their own reality (Delgado, 1990; Ladson-Billings \& Tate, 1995). One's voice is qualified to introduce a counter-narrative that can enable an intellectual unpacking and explanation of the evolution of social discourse, framing of narratives, and the racial remnants in the lives of people of color (Delgado, 1989, 1990). Lastly, CRT scholarship takes on a commitment to social justice through critical liberating scholarship intended to eliminate racial oppression in route of eradicating all forms of oppression that continue to enable disparities of power and subordination (Matsuda, Lawrence, Delgado, \& Crenshaw, 1993; Solórzano, 1997; Tate, 1997).

The tenets of CRT cooperatively offer a theoretical frame and analytical lens for which to examine race and racism where other modes of scholarship have been less effective and/or perpetuate racialized distortions through deficit theorizing (Yosso, 2005). Thus, a CRT viewpoint shifts the research lens away from a deficit stance directed at communities of color to purposefully glean a deeper, fuller understanding of the actual and potential means, cultural assets and sociocultural wealth that exist within and by communities of color (Solórzano \& Solórzano, 1995; Villalpando \& Solórzano, 2005; Yosso, 2005). Tara Yosso (2005) postulates that deficit thinking subsists as one of the most prevalent forms of contemporary racism within US institutions of education. The juncture of deficit thinking and education tolerate schooling and programmatic efforts to default to a banking educational model. Freire (1973) pointedly critiques and interrogates the banking educational model by which purportedly passive students are symbolically filled with the cultural knowledge, skills and experiences deemed necessary for cultural outcomes and their 'appropriate' development. From this perspective, race often takes on the coded nomenclature of "cultural difference" in schooling settings (Yosso, 2005, p.75). Yosso employs a critical race theory (CRT) lens to challenge notions of deficit thinking and better understand the empowering potential of communities of color. She argues Bourdieu's work and other traditional views on cultural capital have been appropriated to suggest some communities (i.e., white, 
middle class) possess a greater degree of cultural wealth while other communities are culturally poor concerning one's capital. In this frame, the means, knowledge and skills of the white, middle class are privileged and all others are judged in comparison with this normalized community (see Yosso, 2005).

Accordingly, Yosso (2005) departs from a traditional view of sociocultural capital narrowly defined by white, middle class and similarly limited views of wealth by situating the research lens on the experiences of people of color in a critical, historical context to expose accumulated assets, knowledge, skills and resources that exist in the histories and lives of communities of color. Through this perspective, the sociocultural wealth of a community can then encompass a collection of knowledge, skills, abilities and contacts possessed and used within and by communities of color to persist and contest macro and microforms of oppression (Yosso). As such, the research and analytical lens of CRT is used in the current study to extend the literature on social and cultural capital to examine the influence of race and racial ideology and provide a robust framework for understanding the developmental experiences of black student-athletes at historically white institutions ${ }^{1}$.

\section{Methods and Context}

\section{Research Design}

The present research used a critical collective case study design (Stake, 2005; Yin, 2014). The collective case study approach authorized a robust exploration within and across settings to investigate the similarities and differences between the cases (Stake, 2005). Broadly, the questions framing the research inquiry were: a) What role might race play in black student-athletes' accrual of social capital? b) How is social capital understood and generated through program design and pedagogy for the development of black student-athletes in historically white institutional (HWI) settings? The conceptual lens of social capital theory (see Bourdieu, 1986; Coleman, 1988, 1990; Lin, 1999; Portes, 1998; Putnam, 1993, 1995) and critical race theory (see Ladson-Billings \& Tate, 1995; Solórzano, Ceja, \& Yosso, 2000; Yosso, 2005; Tate, 1997) were drawn upon to explore stocks of capital and social relations germane to black student-athletes while also exploring the nuance ways by which race and racism influence their development, particularly related to social capital, and their broader experiences within white settings. Using a collective case study approach (Stake, 2005), this study focused on two student-athlete programs that uniquely share similar programmatic efforts to enhance the development of student-athletes from under-served racial groups.

\section{Data Collection}

Data collection for this collective case study occurred at two NCAA member institutions of higher education whose respective athletic departments participate at the highest level of intercollegiate athletics, Division 1. Each site in this paper will be referred by their pseudonyms-Blue University and Yates State. The multisite data collection spanned the course of two years and included one 90-120 minute semistructured interview with thirteen participants. In addition to interviews, 
observational notes (Yin, 2014) were taken of participants and those included in their social ties, formal and informal participant interactions with program and other departmental staff, faculty and university staff, and the local community. Relevant documents, such as program curricula and fliers, were also reviewed to aid the triangulation of data sources.

\section{Research Settings}

The Athletics Department of Blue University coordinates an annual leadership program, which will be referred to as The Ship, that aims to advance the development of underserved racial/ethnic minorities, particularly black student-athletes, through educational programming and mentorship. This program is coordinated through the collaborative efforts of Blue's athletics department and the black student cultural resource center on campus. The mentor relations organized in The Ship included a mentee (i.e., student-athlete) in the program being connected with a student-athlete peer mentor and an adult who was a former student-athlete at the collegiate level. In a similar vein, the athletics department of Yates State hosts an annual studentathlete mentoring program, which will be referred to as the Anchors, which assigns two to three student-athlete mentees to a designated mentor from the university community. The Anchors program emphasizes "connecting student-athletes" to "create access to a resource to obtain their educational and personal goals" using faculty and athletics staff.

\section{Researcher Reflexivity}

Reflexivity is commonly demonstrated by use of first-person language and the transparency of one's decisions and rationale leading into and throughout the research process (Berger, 2015). Researcher reflexivity provides an opportunity for critical self-evaluation by the researcher to understand how one's own experiences and understandings of the world and intersections of the researcher's positionality may affect the research (Berger, 2015; see Milner, 2007; Morrow, 2005). Drawing upon this tradition, I, the researcher, served as the primary instrument through which data were generated and analyzed (Merriam, 2002; Pezalla, Pettigrew, \& Miller-Day, 2012). I spent nearly a year at each site as a participant-observer over the two years the present research was conducted. My role as a participant-observer allowed me to develop a positive rapport with all participants in each program. Due to employment changes, I continued the research as an external-observer at Blue University while serving as a participantobserver at Yates State. I approached this study as a former Division 1 black collegiate student-athlete at a large HWI of higher education. Following my tenure as a collegiate student-athlete, I have spent several years working closely with diverse student-athlete populations in various roles within intercollegiate athletics including coaching, administration and student-athlete affairs-all at HWI settings. As a qualitative researcher, my epistemological lens commonly reflects a critical paradigm to explore the nuanced experiences and complex phenomena concerning the dyadic worlds of being a student and athlete at a HWI. Accordingly, I find the insights of a CRT perspective meaningful to contextualize both broader and comprehensive understandings of how the social construct of race and 
manifestations of racism impact the development of student-athletes and their yields of capital.

\section{Participants}

Approval by the human subjects internal review board was obtained at both Yates State and Blue University to conduct the present research. Subsequent to these approvals, purposive sampling strategy and snowball sampling techniques (see Patton, 2002; Teddlie \& Yu, 2007) were used to direct the participant recruitment process. The assistance of directors and program coordinators who led the Ship and Anchors were enlisted to provide elicited feedback and recruit participants from their respective programs. Both programs were selected due to research interests in interviewing and observing the unique population of Division 1, black student-athletes apart of a student-athlete development program for under-served racialized group members. These programs and student-athlete population were the focus of this research to harvest meaningful findings that may advance understandings of social capital and the development of black athletes in historically white campus settings. Program staffs were explained the purposes of the research and asked to identify potential participants. Subsequent to meetings with staff and then potential participants, a total of $N=13$ black student-athletes, seven from Yates State ( $n=3$ males; $n=4$ females) and six from Blue University ( $n=4$ males; $n=2$ females), agreed to participate in the study. Participants ranged from freshman to seniors ( $n=2$ freshman; $n=3$ sophomores; $n=5$ juniors; $n=3$ seniors) and represented a range of sports including football, basketball, volleyball, track and field, and softball (see Table 1).

\section{Table 1 Participant Descriptions $(N=13)$}

\begin{tabular}{llllll}
\hline Institution & Pseudonym & Class & Sport & Gender & Major \\
\hline Yates State & & & & & \\
& Anthony & Jr. & Football & M & Kinesiology \\
& Alana & Soph. & Volleyball & F & Secondary Education \\
& Raheem & Jr. & Football & M & Communications \\
& Anneesa & Sr. & Softball & F & Biology \\
& DeAngelo & Sr. & Basketball & M & Economics \\
Blue & Isabelle & Fresh. & Basketball & F & Undeclared \\
& Donniversity & Jr. & Basketball & F & Economics/Sociology \\
& & & & & \\
& Alezia & Soph. & Volleyball & F & Criminal Justice \\
& Damarious & Sr. & Football & M & History/Agriculture \\
& Kenyon & Jr. & Track & M & Ethnic Studies \\
& Martin & Soph. & Football & M & Undeclared \\
& Kasey & Fresh. & Track & M & Business \\
& Mya & Jr. & Basketball & F & Sociology \\
\hline
\end{tabular}




\section{Procedure and Analyses}

Data collection and data analysis occurred in a concurrent and continuing manner for necessary adjustments as warranted (Creswell, 2003; Merriam, 2002). The constant comparative method enabled a systematic interpretation of data by identifying commonalities and developing categorized codes and themes to synthesize data (Glaser \& Strauss, 1967). After several readings of participant-approved transcripts, any commonalities located and interpreted while supportive data threads (Patton, 2002) resonating with and deviating from observational notes were identified. All emergent themes were identified and coded (Creswell) with a focus on how studentathletes' perceived, discussed and created meaning of their social ties and networks and their experiences in historically white campus settings. Drawing from a CRT lens, the researcher's read of the data on how the structuring of programing and social relations present in the data illuminated certain understandings related to privilege, racism, deconstructing whiteness, immediate and broader implications of racial inequities, and social justice (e.g., Bonilla-Silva, 2009; Ladson-Billings, 1998; Singer, 2005). Overarching themes emerged from coded data (e.g., finding community, reshaping perspectives, cultivating, cultural gaps, new links, interdependence, self-defining) to demonstrate similarities and dissimilarities between The Ship and Anchors and to build an explanation of how participants make meaning of developing social networks and social capital, draw from sociocultural wealth resources, and consider the role of race in their experiences (Yin, 2014).

\section{Findings}

This collective case research investigated black student-athletes' experiences and perceptions within and across two independent developmental program case settings, The Ship and The Anchors. Two thematic findings emerged from the data analysis characterized as 1) Connected with and through community and 2) Cultivating cross-cultural ties. Collectively, the findings illustrate how black studentathletes' begin to make meaning and accrue social capital through developmental programs while negotiating the role race has on their experiences. However separately, the individual themes typify the unique programmatic position surfacing from the purposes set forth and participants' perceptions of their respective program. The thematic findings are presented in this section in accordance to their principal alignment to case $\mathrm{A}$ and case $\mathrm{B}$, respectively. The subsequent section will expound on these findings to further discuss the respective themes from each case as well as how the themes partially cut across both cases.

\section{Case A: The Ship}

Connected With and Through Community. Two weeks after the school year began, a flyer was circulated throughout the athletics department to coaches and staff members to announce the 'launching' of The Ship - a popular nickname of this particular student-development program within Blue Athletics. At the center of this flyer was Blue University's athletics logo, with the prominent school colors removed from the body of the logo and replaced with the smiling faces of past black studentathletes from last year's program. The official name of the program was listed above this appropriated logo while the words "WE ARE THE SHIP" was printed below. 
Intercentricity of Race. At the first gathering, the program coordinators greeted all mentors and student-athletes with a hand shake while saying, "Welcome to the Ship!" This same welcome was repeated for every individual at the start of all other gatherings the rest of the school year. Shortly thereafter at this first meeting, Damarious, a senior student-athlete featured on the flyer and self-described as "a three year veteran on the ship" stood before the group and gave an introductory speech beginning with the phrase, "We are the ship, All else the sea." He explained that these were words spoken by Rube Foster, the founder of the renowned negro baseball league, proclaiming a vision and strategic plan by which he asserted the black community would have to self-organize to compete in a professional level of baseball comparable to or better than that of major league baseball (Nelson, 2008). Foster's proclamation to organize from within and to lean upon the support of the black 'community' — an in-group system of support-is set to the backdrop of an era of baseball and American society governed by a wide-spread gentleman's agreement that systemically institutionalized de jure and de facto racial segregation. In front of an audience of his peers, staff members, and several coaches in attendance to show support for their athletes' involvement, Damarious stated,

It is us [black] student-athletes and the mentors in this room that are the ship today. We have to come together find a community in this room that we can use to set our own course in a sea that is not always so easy to navigate. We are few in numbers on this campus and we shouldn't think of this as an awful situation. Rather we, the ship, is both who we are and the means to our survival. The ship is where we can come together to connect and build each other up and keep each other strong. (observation notes, p.3)

Damarious's comments here highlight the foundational perspective rooted in the members and organizers involved in the Ship. In particular, his message keenly captured a collective perception of their experience as black student-athletes at Blue University as analogous to that of the premises and purpose by which Rube Foster sought to organize the Negro Baseball League. His comment depicts the linkage of historical race relations that shaped the experience of black participation in sport within a racialized precivil rights society to the modern postcivil rights era where racial disparities and a climate influence by race and racism are still present. Another point of distinction here is the identification of the Ship as being a community of people, while also offering this community a modus to successfully navigate the institutional climate that considers the racialized conditions.

Bonds of Care, Trust and Support. Participants' opportunities to develop trust with their mentors through the facilitated conversations in the Ship's program contributed to a deepening perception of connectedness to those within their social relations. In his interview, Damarious stated:

Since I was a freshman, when I walk into most classrooms here, I'm usually walking into a sea of white faces. I feel like everywhere I go I'm the one or the one of just few faces that doesn't look like the rest. The Ship is where I can just be! Where people understand what its like to be a black student on this campus. It's a family atmosphere where we can talk like we're family. Crack jokes on each other but at the same time create that community of support we 
all need. It may be a different time or for different reasons, but we all come back to the Ship for support. And that's what its [the Ship] here for. (Interview transcript, p.4).

The core element to the community of support, as noted by Damarious, was a salient sense of trust perceived by participants involved in The Ship. A common response to questions concerning how participants perceived a feeling of forging community within the Ship was illustrated by their readings of the role that trust played in social relations stemming from the Ship. A women's basketball player, Mya, shared her thoughts regarding trust, stating

When we come to the ship we get to let the guard down. I never let anyone get too close. It's just not really been worth it for me. But at the Ship you're forced to be a little vulnerable as we talk about different things like getting this education or what we're going through or dealing with. I've been realizing that we're [black athletes in the program] kind of going through it in kind of the same ways. When I talk with my mentor or when they are sharing things about themselves with me, we're building that trust that connects us. (Interview transcript, p.19)

Like Mya, Keynon, Alezia, and Martin also identified trust as being a central component to what enables student-athletes to find refuge in the supportive community of social relations between athletes and their mentors. Alezia stated that the "relationship with her mentor and some of the athletes in the Ship" has evolved to a level of being "affirming in a way that what I take from here is going to pay off for me in the future" (Interview transcript, p. 15). Accordingly, Keynon discussed that what he takes from the Ship are the "networks of relationships with people that know first hand what its like as a brotha [black male] on this campus and they validate how I feel when I'm struggling" (Interview transcript, p. 14-15). Damarious added, "we all click together pretty well because we all get the [black] struggle, but we also support each other to survive through the struggle so that we don't leave anyone our their lost and not able to find their way" (Interview transcript, p. 8).

The benefits derived from the social relationships participants experienced with their mentors, staff and faculty apart of the community of the Ship extended beyond cultivating a consciousness regarding race relations and fostering a community of support and trust. Participants committed their energies to nurturing these social relations because they also "perceived a return on investment" in the form of meaningful knowledge and social and practical skills deemed useful in their immediate and distant futures (Interview transcript, pp. 12, 19, 26). In his response to a broader question of what it was that he seemed to get out this student-athlete development program, Kenyon replied:

Here, you get that real feeling that we are people that matter more than just our worth as an athlete. It's one thing to be to liked by people because they need you to get these wins or appreciate your athletic talent. That's cool and all, but it's another thing for a community of people to genuinely care about how you're doing, what we care about and who we become. This Ship is about us and our needs; bigger than the game. The Ship is about drilling down into what make us who we are and then thinking about how we show up today; what we need to be successful tomorrow after our playing days. (Interview transcript, p. 12) 
In Kenyon's comment above, he uses the words "...real feeling..." to underscore an authenticity captured by the intentionality and care expressed through social ties within the Ship's program. The social networks, as characterized by Keynon during his interview, are realized as value added in terms of resources gained in stocks of social capital to fulfill the palpable needs and knowledge gaps that might harvest a viable return to him and the other participants later.

In correspondence to this notion of how networks of social relations provide a beneficial yield to participants, Kasey reveals:

In most cases, the mentors and staff members have already laid the groundwork of building connections through professional relationship or and they are familiar with the resources that I want access too. So I come here always ear hustling around the room. You know, listening in on the conversations to hear if a person has a network that I need to tap into. This is how I've made it. Just listening for what and who a mentor knows and then connecting with them to eventually tap into their pipeline (Interview transcript, p.22).

Likewise, Alezia and Mya quite emphatically queried their mentors to consider how broad or extensive their networks might actually be and then to advocate on their behalf and introduce them to these potential social ties to grow their own networks. Notable in the observation notes of participants' formal and informal interactions and throughout participant interviews was their persistent inquiry of whom else their mentors might know that could be a provide a returned benefit. Such inquires were probes to unearth and broaden one's network of viable social relations for the opportunity to capitalize on expanded social ties. For example, Mya stated:

Benny (mentor pseudonym) knows a lot people around this campus and in the community. He doesn't always remember that he might know so-and-so unless I press [question] him to think if he might know someone that can help me do a specific thing or get connected to another someone important for me to accomplish what I'm trying to accomplish. I have to keep asking 'now who else do you know' or 'don't you know so-and-so? (Interview transcript, p.28)

These types of statements demonstrated that the Ship provided an assembly of social networks that nurtured perceptions of a meaningful community driven by care, support, senses of trust and connectedness. The community within the Ship served a valuable role in the ways by which black student-athletes developed understandings of how the social construct of race shaped their experiences within their institutional settings.

\section{Case B: The Anchors}

Cultivating Cross-Cultural Ties. The Anchors program is a student-athlete development program managed by the Yates Athletics Life Skills coordinator. All mentors in the Anchors program were race/ethnic minority university staff or faculty selected by the program coordinator. The use of the name Anchors is drawn from participants' characterizations of the perceived role that these mentors play in the social network of student-athletes. Donna stated: 
Because I didn't know her at first, it took some time to get know each other better. Honestly, she would try to reach out to me more than I. But now, she's that anchor for me when I'm just filling lost or need to come back to get grounded. She's home base for me. I take that initiative to go venturing off to figure things out as best I can, but I know where to come back, or better yet, who to come back to with questions. All because she's my anchor! (Interview transcript, p.4)

When asked to describe what his relationship was with his mentor, Raheem's assessment echoed that of Donna and the other participants. While sharing a story in his interview, Raheem captured his approach to the relationship with his mentor saying:

I see it like this - I know I can always call on Ray (his mentor) when something comes up and I feel like I need some advice, need to ask a difficult question, or just want to call to say what's up. He doesn't really hover over me, but I know he's there. Like that invisible lifeline I got in the back pocket at all times. I feel like I'm a confident person, but just having the relationship with Ray helps when I have questions or need to have a moment. (Interview transcript, p.9)

Like others, Raheem perceived his mentor as an anchoring figure within the structure of their social relationship. The social tie present between mentors and student-athlete mentees in the Anchors program facilitated in-group interactions that offered support to navigate experiences with individuals and systems representing an out-group society. The role of mentors involved in Anchors served also as a social-cultural cornerstone role for which athletes returned to as necessary when seeking a critical sounding board for constructive support, building selfconfidence, and being empowered to face and discover new experiences beyond the black Anchors community.

"Bi-lingual"Competence. The anchors, or otherwise mentors, were persistently encouraged by the program coordinator and staff to help their mentees explore and initiate cross-cultural ties that might broaden their networks. To accomplish "extended cross-cultural networks", as described by a staff member, there was a programmatic emphasis for athletes' to develop a 'bilingual' competence. In this context, bilingual competency suggests black student-athletes might effectively negotiate the pervasive, privileged cultural norms, behaviors and systemic racialized beliefs and discourse that discernibly and covertly present themselves at and within the campus setting of this HWI and in the community. While describing their experiences as a black student at Yates, DeAngelo and Alana's insights illuminate how each aims for and struggles with learning to be bilingual to build her social networks that include such cross-cultural ties.

DeAngelo: In a real sense there aren't enough of us to solely rely on us to make it. It's the world we live in; I have to build relationships with my white professors and white students. Those relationships are just essential to get places where we don't usually get the easy opportunity to walk right into. So we have to figure out how to fit into their world. (Interview transcript, p.17)

Alana: I see my life as not only within the main story line, but it also plays out in those racist comments that live beneath an article posted online. I'm always 
skeptical when I meet them [white peers] or my Profs. Don't get me wrong - I play the game. But I want the relationship, but I can't ignore the fact that I can't see the real person in most cases because they're like the anonymous comments section that shows how some people really feel about us walking around here. I think my teachers immediately see me as intimidating, but its only because I we see things differently. Not always, but sometime I have to present myself almost like I' $m$ accommodating their insecurities about me. (Interview transcript, p.21)

Participants' narratives for negotiating cross-cultural relations and developing their ability to essentially code-switch through social ties across racial bounds at Yates reveals how the presence of white privilege and the whiteness manifests in their experience and ability to generate a broader network of social capital.

Thriving Tomorrow. A familiar focus communicated by participants during their interviews and observed in the formal and informal exchanges throughout Anchors was the concept of "preparation to thrive in the changing world" (Anthony's transcript, p. 14). Isabelle recounted how she and her mentor spent quite a bit of time discussing "what the future holds and how she will have to show up as the world changes" (Isabelle's transcript, p. 26). She shared in her interview:

I get that its not just about feeling good here or even trying to quote on quote make it here. We talk about how to learn in the here and now, but for tomorrow. So he's giving me the tools for something greater and preparing me to not only how to get acclimated and adapt here at Yates, but also prepared for life after Yates. (Interview transcript, p.26-27)

Weeks after her interview, Isabelle was having with a fellow student-athlete in the Anchors program. In the course of their dialogue, she offered the perspective of her mentor, Alvis, as advice to her peer. Isabelle stated:

He says you can't think of campus as not the real world. It is! Alvis has shown me over and over, in different ways, how some of the challenges we face as a campus now will be more of the challenges you and I will face later in life. For example, more and more students are coming here from different places. We have to be able have a functional relationship with different people. But the majority of white people in your classroom could look like where you might work. Think if you ended getting a job here in town. (Observation notes, p.6)

In extension to his comment earlier, DeAngelo echoed the sentiments of his peers further explaining his position on fostering cross-cultural connections with others as mean to establishing new opportunities. He states:

I've been blessed to build connections with people that have opened up new doors to things that didn't even seem possible for me or even us [black students] before. I'm beginning to get more of an inside look at a world that I could only see from the outside. And from the outside looking in you just don't understand how it works till building those relationships.

Similarly, Anneesa's justified the benefit taking the time to practice and developing cross-cultural relations with those across the Yates campus on the "inevitable 
cultural shifts in demographics that are on our society's horizon." Anneesa reflected on the mentorship she receives from her "anchor:"

We talk about my generation and the expectations of us as the next generation of leaders. Going forward, Angie pushes us with questions after questions to think about what will be expected of us as the torch is handed off. We have to be aware and know ourselves. We have to have that anchor! But we also have to be able to cross those traditional boundaries because that's what will be demanded of those of us that are going to be able to get things done. Tomorrow's careers and even the neighborhoods are becoming more diverse. So I have to know how to understand and work with all them mixes of people by race or whatever. (Interview transcript, p. 8)

The comments of student-athletes in the Anchors program revealed an intentionality to develop cross-cultural relations, cultivate competences to traverse between social and cultural norms and behaviors, while preparing to be citizens in a world experiencing constant sociocultural change.

\section{Discussion}

Social capital has historically been a cornerstone in the shared experience of black people in American society (Morris, 2004). The lens of critical race theory, in the current study, assisted in filling a void in understandings of forms of capital by way of critically examining how race and racial ideology influence black student-athlete development and one's broader experiences. As seen in this study, the intersecting societal institutions of sport and higher education embody a sociocultural climate for which black persons and their accrual of social capital are influenced by their navigation of overt and clandestine racial discourses, ideology and inequity. Through a collective case study approach, this research investigates black student-athletes' accrual and meaning-making of social capital while involved in culturally-relevant student-athlete developmental programs located at two HWI sites. The subsequent discussion points to particularly relevant pedagogical practices that may better serve the capital needs of black student athletes with consideration of the sociocultural milieu for which their development is fostered. The research design enabled a rich exploration of the experiences of black student-athletes within and across uniquely designed programs while also an extrapolation of both similarities and differentiations between case settings (Stake, 2005). Social capital, in this study, was framed as the sum of actual and potential resources that exist within, are accessible through, and are a derivative of the social ties of a relational network possessed by a person or community of color (see Bourdieu, 1986, 1993; Putnam 1995; Yosso, 2005). Although each of the student-athlete programs that contextually situate this study were grounded in a focus on black student-athlete development, the findings expose similarities and nuanced differences in social capital between participants and these programs.

\section{Forms of Social Capital}

Both the Ship and the Anchors development programs reflected cellular forms of intentionally organized communities ripe for facilitating compelling forms of social 
capital for black student-athlete participants. In similar fashions, each program was seemingly grounded in the premise that their student-athletes would benefit in developing meaningful interpersonal resources and social capital through programmatic facilitation of a network of social ties. In each the Ship and the Anchors, the networks of social ties themselves were constituted by perceptions of a developed level of trust stemming from mutual expectations linked to a perceivable authenticity of individuals and an onus to make oneself available to another. Coleman (1988) contends social capital like that observed in the Ship and Anchors programs is dependent upon manufacturing trustworthiness that is derived from the establishment of obligations and expectations between actors.

Notwithstanding, Putnam (2000) contends all forms of social capital are not equal, shedding a particular light on bonding and bridging types of social capital. The student-athletes' meaning-making of their social ties are situated within the dimensional concepts of bonding and bridging social capital located in Putnam's (2000) multidimensional conceptualization of social capital. Based on the data, student-athletes' social capital developed through the Ship principally evokes Putnam's characterization of bonding social capital. Bonding social capital is based on networks that present a similarity among actors and social structures with regard to such demographic factors as race, ethnicity, age, socioeconomics, role status and/ or education. In this case study, race was a core factor for which the deeper bonds and connectivity between individuals in the program were cultivated. The element of bonding as a dimension of social capital is captured within the connecting of predominantly homogenous social ties leading to a strengthening, or reinforcement of values and characteristics upheld within and by such networks (Putnam, 2000). As such, the framing of "Welcome to the Ship" to invite mentors and mentees into a space of support drawn from an immediate recognition of race reflects a reinforcing discourse to strengthen the bonding of black athletes and their black mentors in the context of a HWI. Here, the social networks with a shared homogenous identity and experience, in this case being black, reify the exclusivity of their racial identity through social relations that embolden introspective examination. As evidence of a high degree of bonding social capital, the student-athletes of the Ship, in particular, cited a sense of comfort and perseverance as an underserved population with regard of finding community to traverse the sociocultural climate of their HWI.

Consequently, the potential for the preservation of social separations through bonding social capital heighten the chances of negatively bolstering antisocial behaviors perpetuating social inequities for homogenous social networks. Accordingly, a common reactive behavior promoted by the Ship was for student-athletes to return and find solace with those involved in the Ship nearly to the exclusion of those outside the Ship. Essentially, the Ship constructed a strong sense of social capital for student-athletes, yet almost consigned to the social ties created within the program. To this point, Putnam refers to this quality of bonding social capital as "the darker side of social capital" (pp. 350-351). Whereby, a high degree of bonding social capital can be limiting by its potential to perpetuate siloes of social capital that offer support, yet do less to foster bipartisan or multilingual skills that enable one to speak across the sociocultural isles of race.

In contrast, the narratives furnished from the Anchors program echoes what Putnam (2000) describes as bridging social capital. Bridging, in this context, refers to the crosscutting ties (Paxton, 1999), which construct viable channels for access 
and information that extend beyond the homogeneity of networks and social structures. It is the construction of networks or social structures that reach beyond the scope of homogenous social ties enabling a ripe environment for individuals to acquire bridging social capital. The cross-cultural emphasis to broaden the social networks of student-athletes in the Anchors program underscores this notion of developing bridges that connect heterogeneous social ties. The narratives revealed participants acknowledged the usefulness of exploring a different make-up of social relationships to possibly yield a positive return in ways homogenous social ties might not. There most certainly was a level of bonding social capital evident in the Anchors program. In observation of participants, the construction of bonding social capital emerged as a clear footing to the program. However, unlike the Ship, the focus of the Anchors looked to use this footing to initiate dialogue that inspired student-athletes to explicitly broaden networks cross-culturally. As reflected by the comments of Isabelle, DeAngelo and Anneesa, the expansive range connections fostered by bridging social capital afforded individuals an experience of new found relationships or ties seen as useful for finding out-group or external support, gaining newfound access, and attaining a new wealth of information meaningful to their needs now and/or in the future. The social ties of bridging social capital are conceptually weaker than that of bonding social capital. To this point, the weakness of developing social ties to furnish bridging social capital invoked participants' realizations of the realities and complexities of how race influences their development and experiences.

\section{Social Capital and Critical Race Theory}

Considering the contexts of sociocultural environment by which social ties are developed between and among actors is critical toward understanding the significance of nurturing black student-athletes' social capital. This collective case study revealed that black participants were aware and continually grappled with the racialized experience of being black within their respective HWI and the broader communities. The lens of CRT assisted in unpacking the data through the tenets used in the current study. Their awareness and continual negotiation of race and racism illuminate CRT's tenet of the intercentricity of race and racism. Participant narratives reveal how race influenced their search for or their ability to extend their sense of community (Sarason, 1974; Warner \& Dixon, 2011) and social relations on their campus. Intercollegiate athletic departments, akin to their campus counterparts (i.e., student affairs, academic support services), play a key role in creating meaningful communities that serve to enhance the well-being of its constituents (Warner \& Dixon, 2011, 2013). The interviews with participants bare how the deep rooted, systemic functionality of race played a central role in their self-exploration, their construction of their racialized identity and their presentation of self to others in HWI spaces. Kenyon's statement, "The Ship is about drilling down into what makes us who we are and then thinking about how we show up today" illuminates the sentiments of his peers reflecting how race was key to considering their racial identity and lived experiences in the context and climate of white settings. This study supports research that has demonstrated a perceived sense of community can be elevated by the care, concern and intentionality of athletic leadership and support personnel accompanied by the availability of social spaces that afford 
student-athletes, with shared experiences, the opportunity to build and draw upon their social and cultural capital (Warner \& Dixon, 2011, 2013; Yosso, 2005). Future research must continue to examine how the creation of black student-athletes' sense of community merges with and can be informed by CRT literature in affiliation with understandings social capital and the sociocultural wealth of communities.

Both the Ship and the Anchors programs were not positioned to nor functioned to glorify racial sameness concerning opportunity and experiences. Rather, these programs facilitated social networks that enabled meaningful dialogue for studentathletes to consider the impact of the historic artifacts of race and racism present on their campus and in society that contribute to manufacturing their lived experiences as racialized persons (DeCuir \& Dixson, 2004). Findings across the collective case study also illuminate, from the perspective of the CRT tenet of skepticism of ideology, how student-athletes in these programs de-privileged a color-blind liberalist discourse that commonly pervades normalized social dialogues. Accordingly, the student-athletes reflected upon racial inequities related to the accrual of meaningful social capital often systemically privileged to whites in such settings. Another fundamental tenet of CRT, although not mutually exclusive of other tenets, is the centrality of experiential knowledge by which one is permitted to name their reality through counter-stories. Engaging in counter-storytelling empowers an intellectual deconstruction and explanation of the evolution of social discourse, framing of narratives, and the racial remnants in individuals' lives and communities of color (Delgado, 1989, 1990). Hence, by self-reflecting on their experiences and presenting counter-narratives to notions of color-blindness, the participants were elevating their consciousness of the complexities of race and racism that persist (Ladson-Billings, 1998; Solórzano \& Yosso, 2002).

The weaknesses in the developing the bridging social capital, most evident in the Anchors program, appeared as student-athletes were confronted with manifestations of whiteness (Leonardo, 2002) as they looked to develop cross-cultural, cross-racial social ties with campus faculty and staff. Whiteness here refers to the values, norms, behaviors and racial ideology that consciously and inadvertently privilege the social dominance and self-interests of whites; thus perpetuating racial inequity in a racialized American society. The racial discourse of whiteness, such as color-blindness and unnuanced consideration of equal opportunity disregard the contours of racism, avoid the acknowledgment of persons' lived realities as a result of race, racism and racial legacy, and functions to otherize individuals across racial lines (Leonardo, 2002). Therefore, although developing bridging social capital was a focus and aspirational goal for student-athletes in the Anchors program, their social capital needs intersecting with the realisms of whiteness, as exposed in the present research, unveil a unique sociocultural climate for black student-athletes to navigate.

Traditional conceptions of social and cultural capital are rooted in the practice of privileging the accumulation of specific knowledge, skills and abilities valued by white, middle class culture as the standard by which all other forms of expression of cultures are evaluated in relation to the norm (Yosso, 2005). The lens of CRT offers an opportunity to further such notions of capital by exposing and challenging this function of whiteness and seeing communities of color-even cellular communities of color like the Ship and Anchors-as places of multiple strengths capable of nurturing 'cultural wealth' through various forms of capital. Yosso (2005) argues 
the dynamic processes of various forms of capital, such as social capital, yet also aspirational, navigational, linguistic, familial, and resistant capital contributes to the cultural wealth of communities of color. Building upon the focus of the current study centered on social capital, future research should employ a CRT lens, drawing on the work of Yosso, to investigate how student-athlete programs nurture cultural wealth through various forms of capital.

\section{Purposeful Pedagogy for a Sustaining Capital}

The aim of the current study was to advance an understanding of how a case of student-athlete development programs programmatically and structurally developed social capital for black student-athletes by exploring participant narratives that explicate their meaning-making of social relations and social networks germane to their experiences at a HWI. Across the Ship and Anchors programs, the narratives in this collective case study revealed how the foundational purposes for which each program existed and functioned generated principally different forms of social capital. By utilizing a CRT perspective, this research advances a greater understanding of how race plays a significant role in the experiences of black student-athletes in white settings of higher education and an influencing role in their circumnavigating of sociocultural climates to amass dimensions of social capital. Accordingly, the findings from this collective case study bid further consideration for how best to effectively integrate culturally relevant pedagogical practices with student-athlete development programs to yield worthwhile forms of capital. Thus, a vital implication of this study is a call for pedagogy that better serves black student-athletes as a conduit for nurturing and transmitting forms of social capital.

The seminal work of Ladson-Billings (1995), rooted by a critical paradigm, sketches a theory of culturally relevant pedagogy (CRP) composed of three key purviews: a) academic success through facilitated instruction and learning experiences, b) cultural competence for appreciation and celebration of one's own culture and others, and c) sociopolitical consciousness for solving real-world problems (Ladson-Billings, 2014). The practice of CRP is predicated on conceptions of self and others, developing a community of learners constructed by social relations that are equitable and reciprocal, and conceptions of knowledge. Paris (2012) offers the concept of culturally sustaining pedagogy, not only to build upon CRP, yet also to present a modern alternative frame to reposition pedagogy as "more than responsive of or relevant to the cultural experiences and practices of young people" (p. 95). Thus, culturally sustaining pedagogy seeks to preserve and cultivate cultural pluralism as essential to schooling to afford students to thoughtfully inquire of the solutions that attend to the needs of a pluralistic society, such as the aim in the Anchors program. Paris maintains the vibrancy of a pluralistic society requires "both the many and the one" (p. 95). Thus, creating what equates to an enriching experience for black student-athletes_one filled with academic success as well as personal and social growth-needs a network of both in-group and outgroup relationships. In other words, a robust experience for black student-athletes should help to provide both bonding and bridging forms of social capital. Based on the present research, there exist evidence that programs for student-athlete development are keenly suited as viable sites for these pedagogical possibilities. Furthermore, the pedagogical possibilities that stem from the use of a culturally 
sustaining pedagogy can inspire and generate a sustaining capital for black student-athletes to thrive.

In this context, social sustaining capital begins with developing social ties that preserve an appreciation and celebration of one's own culture and facilitates the sociopolitical, sociocultural consciousness of black student-athletes to find their agency in an ever-changing society. Social sustaining capital is grounded in three propositions: a) social ties enable one to find community that might strengthen one during times of perceived challenge; b) social ties cultivate a social-cultural consciousness that authors a critical understanding of influential systems, the impact of social order, and the complexities of how whiteness and privilege avail themselves to shape the lived experiences of racialized persons; and c) social ties facilitate an acquisition of culturally relevant and responsive competencies and faculties to position oneself as a meaningful change agent in a pluralistic society. Future research should explore ways in which to not only develop meaningful forms capital, but also seek channels that can deliver sustaining social capital for black student-athletes to prosper.

\section{Note}

1. The phrase "historically white institutions" is used instead of a commonly used phrase "predominantly white institutions" to underscore that the gross numbers or percentages of white students have less to do with the composition of the majority than it does with the historical and contemporary racialized infrastructure still in place in institutional settings, which maintains a systemic racialized culture and climate that privileges whites over other racial/ethnic groups of color (Smith, Allen \& Danley, 2007).

\section{References}

Adam, F., \& Rončević, B. (2003). Social capital: Recent debates and research trends. Social Sciences Information. Information Sur les Sciences Sociales, 42(2), 155-183. doi:10.1177/0539018403042002001

Beamon, K., \& Bell, P.A. (2006). Academics versus athletics: An examination of the effects on background and socialization on African American male student athletes. The Social Science Journal, 43, 393-403. doi:10.1016/j.soscij.2006.04.009

Beamon, K., \& Bell, P. (2011). A dream deferred. Journal for the Study of Sports and Athletes in Education, 5(1), 29-44. doi:10.1179/ssa.2011.5.1.29

Bell, D.A. (1992). Faces at the bottom of the well: The permanence of racism. New York: Basic Books.

Berger, R. (2015). Now I see it, now I don't: researcher's position and reflexivity in qualitative research. Qualitative Research, 15(2), 219-234. doi:10.1177/1468794112468475

Bimper, A.Y., Harrison, L., \& Clark, L. (2013). Diamonds in the rough: Examining a case of successful black male student-athletes in college sport. The Journal of Black Psychology, 39(2), 107-130. doi:10.1177/0095798412454676

Bimper, A.Y., Jr. (2014a). Game Changers: The role athletic identity and racial identity play on academic performance. Journal of College Student Development, 55(8), 795-807. doi:10.1353/csd.2014.0078

Bimper Jr., A. Y. (2014b). Lifting the veil: Exploring colorblind racism in black student athlete experiences. Journal of Sport \& Social Issues, 1-19. doi. 0193723513520013.

Bonilla-Silva, E. (2009). Racism without racists: Color-blind racism and racial inequality in contemporary America (3rd ed.). Lanham, MD: Rowan \& Littlefield. 
Bourdieu, P. (1985). The forms of capital. In J. Richardson (Ed.), Handbook of theory and research for the sociology of education (pp. 241-258). New York: Greenwood.

Bourdieu, P. (1986). The forms of capital. In J. Richardson (Ed.), Handbook of theory and research for the sociology of education (pp. 241-258). New York: Greenwood.

Bourdieu, P. (1993). Sociology in question. London: Sage.

Burt, R.S. (1992). Structural Holes: The Social Structure of Competition. Cambridge, MA: Harvard University Press.

Carter, A.R., \& Hart, A. (2010). Perspectives of mentoring: The Black female student-athlete. Sport Management Review, 13(4), 382-394. doi:10.1016/j.smr.2010.01.003

Carter-Francique, A., Hart, A., \& Steward, A. (2013). Black College Athletes' Perceptions of Academic Success and the Role of Social Support. Journal of Intercollegiate Sport, 6(2), 231-246.

Coleman, J.S. (1988). Social capital in the creation of human capital. American Journal of Sociology, 94, S94-S120. doi:10.1086/228943

Coleman, J.S. (1990). Foundations of social theory. Cambridge, MA: Harvard University Press.

Crenshaw, K.W. (1988). Race, reform, and retrenchment: Transformation and legitimation in antidiscrimination law. Harvard Law Review, 1331-1387. doi:10.2307/1341398

Crenshaw, K. (1991). Mapping the margins: Intersectionality, identity politics, and the violence against women of color. Stanford Law Review, 43(6), 1241-1299. doi:10.2307/1229039

Crenshaw, K.W., Gotanda, N., Peller, G., \& Thomas, K. (1995). Introduction. In K.W. Crenshaw, N. Gotanda, G. Peller, \& K. Thomas (Eds.), Critical race theory: the key writings that formed the movement (pp. xiii-xxxii). New York: The New Press.

Creswell, J.W. (2003). Research design: Qualitative, quantitative and mixed methods approaches. Thousand Oaks, CA: Sage Publications.

DeCuir, J.T., \& Dixson, A.D. (2004). So when it comes out, they aren't that surprised that it is there: Using critical race theory as a tool of analysis of race and racism in education. Educational Researcher, 33(5), 26-31. doi:10.3102/0013189X033005026

Delgado, R. (1988). Critical legal studies and the realities of race: Does the fundamental contradiction have a corollary? Harvard Civil Rights-Civil Liberties Law Review, 23, 407-413.

Delgado, R. (1989). Storytelling for oppositionists and others: A plea for narrative. Michigan Law Review, 87(8), 2411-2441. doi:10.2307/1289308

Delgado, R. (1990). When a Story Is Just a Story: Does Voice Really Matter? Virginia Law Review, 95-111. doi:10.2307/1073104

Donner, J.K. (2005). Towards an interest-convergence in education of African American football student-athletes in major college sports. Race, Ethnicity and Education, 8(1), 45-67. doi:10.1080/1361332052000340999

Feagin, J.R., Vera, H., \& Batur, P. (Eds.). (2001). White racism: The basics. Psychology Press. Freire, P. (1973). Pedagogy of the oppressed. New York: The Seabury Press.

Glaser, G.B., \& Strauss, A.L. (1967). The discovery of grounded theory: Strategies for qualitative research. Hawthorne, NY: Aldine.

Gotanda, N. (1991). A critique of "Our constitution is color-blind.". Stanford Law Review, 44, 1-68. doi:10.2307/1228940

Ladson-Billings, G., \& Tate, W.F. (1995). Toward a critical race theory of education. Teachers College Record, 97(1), 47-69.

Ladson-Billings, G. (1995). Toward a theory of culturally relevant pedagogy. American Educational Research Journal, 32(3), 465-491. doi:10.3102/00028312032003465

Ladson-Billings, G. (1998). Just what is critical race theory and what's it doing in a nice field like education? International Journal of Qualitative Studies in Education : QSE, 11(1), 7-24. doi:10.1080/095183998236863 
Ladson-Billings, G. (2014). Culturally relevant pedagogy 2.0: aka the remix. Harvard Educational Review, 84(1), 74-84. doi:10.17763/haer.84.1.p2rj131485484751

Lapchick, R., Fox, J., Guiao, A., \& Simpson, M. (2015). The 2014 racial and gender report card: College sport. UCF Institute for Diversity and Ethics in Sport. Available at http:// www.tidesport.org/2014\%20College \%20Sport\%20Racial\%20\&\%20Gender\%20 Report\%20Card.pdf.

Lawrence, C.R. (1995). The id, the ego, and equal protection: Reckoning with unconscious racism. In K. Crenshaw, N. Gotanda, G. Peller, \& K. Thomas (Eds.), Critical race theory: The key writings that formed the movement (pp. 235-257). New York: The New Press.

Leonardo, Z. (2002). The souls of white folk: Critical pedagogy, whiteness studies, and globalization discourse. Race, Ethnicity and Education, 5(1), 29-50. doi:10.1080/13613320120117180

Lin, N. (1999). Building a network theory of social capital. Connections, 22(1), 28-51.

Matsuda, M., Lawrence, C., Delgado, R., \& Crenshaw, K. (Eds.). (1993). Words that wound: Critical race theory, assaultive speech, and the first amendment. Boulder, CO: Westview Press.

Merriam, S.B. (2002). Introduction to qualitative research. In S.B. Merriam \& Associates, Qualitative research in practice (pp. 3-17). San Francisco: Jossey-Bass.

Milner, H.R. (2007). Race, culture, and researcher positionality: Working through dangers seen, unseen, and unforeseen. Educational Researcher, 36(7), 388-400. doi:10.3102/0013189X07309471

Morris, J.E. (2004). Can anything good come from Nazareth? Race, class, and African American schooling and community in the urban south and midwest. American Educational Research Journal, 41(1), 69-112. doi:10.3102/00028312041001069

Morrow, S.L. (2005). Quality and trustworthiness in qualitative research in counseling psychology. Journal of Counseling Psychology, 52(2), 250. doi:10.1037/00220167.52.2.250

Nelson, K. (2008). We are the ship: The story of Negro League baseball. New York: Hyperion.

Paris, D. (2012). Culturally sustaining pedagogy: A needed change in stance, terminology, and practice. Educational Researcher, 41(3), 93-97. doi:10.3102/0013189X12441244

Patton, M.Q. (2002). Qualitative research and evaluation methods (3rd ed.). Thousand Oaks, CA: Sage.

Paxton, P. (1999). Is social capital declining in the United States? A multiple indicator assessment. American Journal of Sociology, 105(1), 88-127. doi:10.1086/210268

Pezalla, A.E., Pettigrew, J., \& Miller-Day, M. (2012). Researching the researcher-asinstrument: An exercise in interviewer self-reflexivity. Qualitative Research, 12(2), 165-185. PubMed doi:10.1177/1468794111422107

Portes, A. (1998). Social capital: Its origins and applications in modern sociology. Annual Review of Sociology, 24, 1-24. doi:10.1146/annurev.soc.24.1.1

Putnam, R.D. (1993). The prosperous community: social capital and public life. The American Prospect, 13(4), 35-42.

Putnam, R.D. (1995). Bowling alone: America's declining social capital. Journal of Democracy, 6(1), 65-78. doi:10.1353/jod.1995.0002

Putnam, R.D. (2000). Bowling alone: The collapse and revival of American community. New York: Simon and Schuster. doi:10.1145/358916.361990

Sarason, S.B. (1974). The psychological sense of community: Prospects for a community psychology. San Francisco, CA: Jossey-Bass.

Singer, J.N. (2005). Understanding racism through the eyes of African American male student-athletes. Race, Ethnicity and Education, 8(4), 365-386. doi:10.1080/13613320500323963

Smith, W.A., Allen, W.R., \& Danley, L.L. (2007). "Assume the position...You fit the description:" Psychosocial experiences and racial battle fatigue among African 
American male college students. The American Behavioral Scientist, 51(4), 551-578. doi:10.1177/0002764207307742

Solórzano, D.G. (1997). Images and words that wound: Critical race theory, racial stereotyping, and teacher education. Teacher Education Quarterly, 24(3), 5-19.

Solórzano, D., Ceja, M., \& Yosso, T. (2000). Critical race theory, microaggressions, and campus racial climate: The experiences of African American college students. The Journal of Negro Education, 69(1/2), 60-73.

Solórzano, D., \& Solórzano, R. (1995). The Chicano educational experience: A proposed framework for effective schools in Chicano communities. Educational Policy, 9, 293-314. doi:10.1177/0895904895009003005

Solorzano, D.G., \& Yosso, T.J. (2002). Critical race methodology: Counter-storytelling as an analytical framework for education research. Qualitative Inquiry, 8(1), 23-44. doi:10.1177/107780040200800103

Stake, R.E. (2005). Qualitative case studies. In N.K. Denzin \& Y.S. Lincoln (Eds.), Handbook of Qualitative Research (pp. 443-467). Thousand Oaks, CA: Sage Publication.

Tate, W.F. (1997). Critical race theory and education: History, theory, and implications. In M. Apple (Ed.), Review of Research in Education 2 (pp. 191-243). Washington, DC: American Educational Research Association. doi:10.3102/0091732X022001195

Teddlie, C., \& Yu, F. (2007). Mixed methods sampling: A typology with examples. Journal of Mixed Methods Research, 1, 77-100. doi:10.1177/2345678906292430

Villalpando, O., \& Solórzano, D. (2005). The role of culture in college preparation programs: A review of the literature. In W. Tierney, Z. Corwin, \& J. Kolyar (Eds.), Preparing for college: Nine elements of effective outreach (pp. 13-28). Albany, NY: SUNY Press.

Warner, S., \& Dixon, M.A. (2011). Understanding sense of community from the athlete's perspective. Journal of Sport Management, 25(3), 257-271.

Warner, S., \& Dixon, M.A. (2013). Sports and community on campus: Constructing a sports experience that matters. Journal of College Student Development, 54(3), 283-298. doi: $10.1353 / \mathrm{csd} .2013 .0044$

Yin, R.K. (2014). Case study research: Design and methods (5th ed.). Thousand Oaks, CA: Sage.

Yosso, T. (2005). Whose culture has capital? A critical race theory discussion of community cultural wealth. Race, Ethnicity and Education, 8(1), 69-91. doi:10.1080/1361332052000341006 